\title{
Transmodalidade em/e processos de produção: mudando disposições e práticas
}

Jody Shipka*

Tradução: Jailine Mayara Sousa de Farias**

Tradução do texto original: "Transmodality in/and Processes of Making: Changing Dispositions and Practice".

Nota sobre a tradução': este texto foi originalmente publicado em inglês na revista College English, v. 78, n.3, 2016, p. 250-257.

Resumo: Neste artigo, Jody Shipka reflete sobre a natureza multissemiótica das práticas composicionais a partir de uma abordagem transmodal. A autora chama a atenção para a necessidade de mudança de disposições e práticas para abarcar a complexa diversidade de processos, sobreposições, diálogos, semioses, agências e materialidades envolvidas na produção de sentidos. Para além de práticas grafocêntricas, Shipka defende o trabalho com a diversidade como um recurso para a construção e negociação de significados, a fim de expandir a consciência retórica dos estudantes e desenvolver sua fluência composicional, permitindo a reflexão sobre a variedade de convenções, tecnologias, materialidades e práticas mobilizadas no processo composicional.

Palavras-chave: Composição. Transmodalidade. Ensino de escrita.

Abstract: In this work, Jody Shipka reflects on the multisemiotic nature of compositional practices based on a transmodal approach. The author calls attention to the need for changing dispositions and practice to embrace the complex diversity of processes, overlaps, dialogues, semiosis, agencies, and materialities involved in the meaning-making process. Moving beyond graphocentric practices, Shipka argues for the work with diversity as a resource for making and

\footnotetext{
" Professora associada de inglês na Universidade de Maryland, Baltimore, EUA. Autora de "Toward a composition made whole" e editora de "Play! A collection of toy camera photographs". Tem trabalhos publicados na College Composition and Communication, Enculturation, Kairos, Text and Talk, Writing Selves/Writing Societies e outros.

** Professora do Departamento de Letras Estrangeiras Modernas na Universidade Federal da Paraíba (UFPB) e doutoranda no Programa de Pós-Graduação em Letras da Universidade Federal de Pernambuco (UFPE). http://orcid.org/oooo-0002-8369-6589 / jailine.farias@gmail.com

${ }^{1}$ Licença para publicação: "Transmodality in/and processes of Making: Changing Dispositions and Practice" by Jody Shipka. Originally published in College English Copyright 2016 by the National Council of Teachers of English. Used with permission.
}

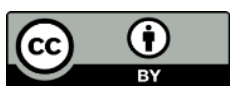

Este artigo está licenciado sob forma de uma licença Creative Commons Atribuição 4.0 Internacional, que permite uso irrestrito, distribuição e reprodução em qualquer meio, desde que a publicação original seja corretamente citada. 
negotiating meanings, in order to expand students' rhetorical awareness and develop their compositional fluency, allowing for the reflection about the variety of conventions, technologies, materialities and practices mobilized in the compositional process.

Keywords: Composition. Transmodality. Writing instruction.

Résumé: Dans cet ouvrage, Jody Shipka réfléchit à la nature multisemiotique des pratiques compositionnelles à partir d'une approche transmodale. L'auteur attire l'attention sur la nécessité de changer les dispositions et les pratiques afin d'embrasser la diversité complexe des processus, des chevauchements, des dialogues, des sémioses, des agencements et des matérialités impliqués dans le processus de création de sens. Allant au-delà des pratiques graphocentriques, Shipka plaide pour le travail avec la diversité comme une ressource pour créer et négocier des significations, pour élargir la conscience rhétorique des étudiants et développer leur aisance compositionnelle, permettant la réflexion sur la variété des conventions, des technologies, des matérialités et des pratiques mobilisées dans le processus de composition.

Mots-clés: Composition. Transmodalité. Enseigner l'écriture.

É comum dizer que a escola é o lugar que requer que as crianças foquem no mundo através da escrita. Pode-se dizer também que a escola é o lugar que insiste, de forma lenta, mas implacável, que o mundo não pode ser conhecido senão por meio das abstrações da linguagem escrita. (Gunther Kress, Before Writing: Rethinking the Paths to Literacy)

Nós desenvolvemos uma noção muito limitada de escrita acadêmica (ou qualquer gênero, na verdade). Nossos textos são convencionais em todos os sentidos da palavra... uma ruptura radical com as convenções de uma forma ou gênero...seria desconcertante - como se faz a escrita da história? que comunidade precisaria disso para compor um boletim informativo? Como isso vai ajudá-lo a obter um emprego? (Geoffrey Sirc, English Composition as a Happening)

Tendo como foco os dois extremos do espectro da aprendizagem/letramento escolar - o ensino fundamental e a universidade, respectivamente - Gunther Kress e Geoffrey Sirc sublinham a questão do poder, da difusão e da inflexibilidade do que Bruce Horner, Tim Lockridge e Cynthia Selfe (2015) denominam como uma "norma-padrão linguística e modal" (em inglês, SLMN, standard language and modal norm) - uma orientação ou expectativa em relação a uma norma única, aparentemente estável, uniforme para compreensão e produção da língua, a qual, como Selfe sustenta, levou à “fetichização dos textos alfabéticos/escritos como a modalidade da razão” (HORNER; LOCKRIDGE; SELFE, 2015, p. 15). Resumindo, e parafraseando Kress (1997) e Sirc (2002), embora existam outras alternativas representacionais/experienciais/linguísticas/materi 
ais, as práticas escolares formais costumam sugerir que não se pode saber, ou, por conseguinte, tornar-se alguém que sabe, senão através das abstrações de certas variedades da linguagem escrita.

Ao traçar o surgimento dos termos multimodalidade e translinguagem, Horner, Lockridge e Selfe (2015) sugerem que ambos são uma resposta a eventos "concretos", ou seja,

o desenvolvimento e aumento do alcance global e uso de novas tecnologias e redes de comunicação para esses eventos; o crescente e cada vez mais inegável fluxo de pessoas e línguas; e o consequente reconhecimento por parte de professores e pesquisadores de composição de que a suposição de uma norma monolíngue e monomodal para a composição - como prática comunicativa e campo de estudo - não é mais apropriada, se é que um dia realmente tenha sido. (grifos meus) (p. 10)

Assim como outros autores apresentados aqui, trato a diferença não como um problema a ser resolvido ou corrigido, mas como um recurso para a criação e negociação de significados. Concordando com Horner et al. (2011), enfatizo a importância de

honrar o poder de todos os usuários de uma língua, de moldá-la para fins específicos; reconhecer a heterogeneidade linguística de todos os usuários de línguas nos Estados Unidos e no mundo; e confrontar diretamente as expectativas monolíngues do Inglês por meio de pesquisa e ensino sobre como os escritores podem trabalhar com e contra, e não simplesmente dentro dessas expectativas (p. 305).

Ainda em consonância com Horner, Lockridge e Selfe (2015), insisto na importância de abordagens de ensino de composição ${ }^{2}$ que tragam "à consciência" o caráter translíngue e multimodal (ou transmodal) dos textos e práticas comunicativas (p. 12), que reconheçam "o grau em que as práticas existentes e passadas estão em desacordo com a ideologia de uma norma-padrão linguística e modal" e que tentem "recuperar toda a gama" de opções comunicativas "cerceadas por disposições

\footnotetext{
${ }^{2}$ N.T.: Embora comumente não utilizemos o termo "ensino de composição" em Língua Portuguesa, optamos por manter essa tradução, por compreendermos que a composição aponta de forma mais ampla para o processo de produção textual, sem se restringir ao ensino de escrita.
} 
desenvolvidas por essa ideologia " (p. 27). Por fim, assim como Horner, Lockridge e Selfe (2015), afirmo que não basta simplesmente trabalhar no sentido de mudar as disposições - para "entender como práticas específicas são multimodais, apesar da cegueira quanto ao caráter multimodal para a qual fomos treinados pela cultura dominante" (p. 7), ou "a reconhecer e reiterar a legitimidade da posição em favor da transmodalidade”(p. 8). Além disso, como argumentam outros autores sobre essa questão (BAWARSHI, 2016; CANAGARAJAH, 2006; 2016; CUSHMAN 2016; GUERRA, 2016), também precisamos nos comprometer totalmente a alterar nossas práticas pedagógicas e de pesquisa - para considerar como o engajamento concreto com diferentes modos, gêneros, materiais, práticas culturais, tecnologias comunicativas e variedades linguísticas afeta nossas habilidades de criar e negociar significados, e como isso afeta o quê e como sabemos, e talvez o mais importante, como pode nos fornecer ainda outras opções para sabermos e sermos, e para nos reconhecermos como alguém que sabe.

\section{Sobre a importância dos processos de construção: trabalhando com (e contra) a agência das coisas}

Tão importante quanto pedir que os alunos (e nós mesmos) considerem e reflitam sobre os aspectos cross-culturais e transmodais dos textos e das práticas comunicativas (por exemplo, algo que pode ser facilitado através da análise de um texto existente através da observação de como, digamos, um texto aparentemente tradicional, monomodal, impresso, alfabético é visualmente disposto de maneiras específicas e tem dimensões táteis e até olfativas), é igualmente, senão mais importante, criar oportunidades para fazer mais e ir além disso. A fim de avançar e facilitar uma maior compreensão a respeito da fluência comunicativa ou composicional, nós precisamos, seguindo Horner, Lockridge e Selfe (2015), possibilitar mudanças tanto em relação à disposição como em relação às práticas. Aprender sobre e trabalhar com diferentes variedades linguísticas, convenções culturais, modos e tecnologias comunicativas (tanto novas como não tão novas, digitais e analógicas) ressaltam os processos de construção, engajamento, remixagem e transformação, os quais, por sua vez, proporcionam 
oportunidades marcadamente diferentes e ricas para experimentar e apreciar melhor os aspectos dinâmicos, altamente distribuídos, translíngues, multimodais e corporificados de toda prática comunicativa (ver também CANAGARAJAH, 2006; FRAIBERG, 2010; PRIOR; HENGST, 2010; PRIOR; SHIPKA, 2003).

Os benefícios de um interesse renovado nos processos de construção são (no mínimo) de duas naturezas. Primeiramente, estimular um tipo de engajamento prático com uma ampla variedade de materiais e recursos comunicativos para além daqueles tradicionalmente/tipicamente associados a práticas acadêmicas e eruditas ajuda a dar suporte ao ponto defendido por Horner e Selfe (2013) em Translinguality/Transmodality Relations, quanto ao fato de que nem todos os textos multimodais são criados da mesma maneira. Mesmo que aceitemos que toda linguagem é multimodal, "nem todos os ambientes para interação linguística são criados da mesma forma em relação a como articulam a combinação entre diferentes modos" (HORNER; SELFE, 2013, p.10). Ademais, Selfe continua: "talvez seja legítimo dizer que novas ferramentas e ambientes de produção oferecem formas bastante distintas para a realização da multimodalidade comparadas às que utilizamos em trabalhos impressos" (p. 10). Como alguém que tem cada vez mais se dedicado à produção acadêmica de vídeos, eu concordaria com Selfe há diferenças salientes, tanto em termos de potencialidades quanto em termos de restrições, alcances e frustrações, e engajamento corporal e afetivo associados com ambas as formas de produção. O conhecimento em vídeos tende a ser muito mais intenso do ponto de vista temporal e envolve muito mais uma dinâmica de tentativa e erro, à medida que procuro e aprimoro novas técnicas para gravação de áudio, edição de imagens estáticas e vídeos, e à decisão de quando e como devo incorporar fala, texto escrito, imagem, movimento e som no projeto. $\mathrm{O}$ trabalho impresso, ainda que reconhecidamente translíngue e multimodal, geralmente parece, por comparação, mais gerenciável, simplificado/linear e, certamente, mais familiar - mas talvez não surpreendentemente, dada a minha história com a produção impressa de textos acadêmicos. Em resumo, com isso, há uma sensação de ter menos questões em jogo, menos componentes para driblar, justapor e reorganizar. Então, embora eu concorde com o argumento de Selfe - de que novos ambientes e ferramentas de produção oferecem diferentes potencialidades para a realização da multimodalidade do que os 
suportados por textos impressos e alfabéticos -, é importante evitar a equiparação entre “novo" e "mais novo" em relação aos textos e práticas digitais ou às novas mídias. Ao fazermos isso, nós negligenciamos o emprego das variedades de linguagens (tanto verbais quanto não verbais, em Língua Inglesa ou não), das ferramentas, das técnicas e dos ambientes anteriores, e talvez mais familiares, que podem ser usados de maneiras novas, remixados, transformados para atender a novos e criativos propósitos (ver, por exemplo, o estudo de Sohan (2015) sobre práticas de produção de colcha de retalhos). Outros exemplos que vêm à mente incluem: compor uma pesquisa, um texto argumentativo sobre sapatos, uma camisa ou projetá-lo como um jogo de tabuleiro; a criação de uma dança persuasiva ou uma performance ao vivo; desenvolver um site composto de texto e videoclipes com várias línguas e/ou falantes; escrever um e-mail, um memorando ou uma currículo utilizando placas de argila; ou criar uma página do Facebook ou uma série de tuítes para apresentar uma pesquisa e desenvolver um argumento. Estas são indiscutivelmente variedades de linguagens, práticas e tecnologias com que os alunos podem estar familiarizados, embora talvez não para fins acadêmicos.

Um segundo benefício de atentarmos para os processos de construção (incluindo a produção de textos mais usuais/tradicionais, aparentemente monomodais e monolíngues, bem como aqueles que empregam múltiplos recursos semióticos e variedades da língua) é que isso ajuda a esclarecer os aspectos altamente distribuídos, corporificados, translíngues e multimodais de toda prática comunicativa, algo que é com frequência negligenciado ou invisibilizado nas análises finais de textos finalizados, produtos, ou performances. Isso propicia, nas palavras de Bruno Latour, uma visão do que está por trás da cena, ou dos "bastidores" das práticas de produção (LATOUR, 2005, p. 89).

Evidenciar os vários textos, ferramentas, estratégias, práticas e participantes tanto humanos como não humanos - que desempenham um papel no suporte, facilitação, alteração e, às vezes, até a restrição ou proibição da produção de um texto focal, produto, ou performance nos permite mover para além do antropocentrismo ou de uma noção antropocêntrica (human-centric) de agência, efeito e colaboração. Jay Jordan (2015) sugere que essa mudança de foco poderia ser especialmente benéfica a abordagens translíngues, muitas das quais tendem a ser "constrangidas por uma 
insistência implícita de usuários humanos elementares discretos" (JORDAN, 2015, p. 368). Jordan insiste na importância de fazer perguntas críticas sobre a língua e as práticas de linguagem ao mesmo tempo em que "produtivamente difunde atenção para os entornos dos materiais produtivos que não podem deixar de informar, influenciar e permear as atividades cotidianas de linguagem" (p. 363). Como Jordan, então, eu defendo que nossas abordagens sobre esse processo precisam evidenciar as ações e intenções de escritores/compositores assim como aquelas oferecidas pelo que Ben Highmore (2010) chama de "mundo das coisas" (p. 58), ou o que Jane Bennett (2010), em Vibrant Matter, chama de "poder das coisas" - "a curiosa capacidade das coisas inanimadas de animar, agir, produz efeitos dramáticos e sutis" (p. 6). Em termos simples, nós precisamos considerar, não apenas a agência humana, contribuição e intenção, mas também ver o humano, ver questões de agência, efeito e afeto, como distribuídos num complexo "campo ontologicamente heterogêneo" (BENNET, 2010, p. 23; ver também PRIOR; SHIPKA, 2003).

Em artigo recentemente publicado na College English, Laura Micciche (2014) afirma que os "principais instrumentos da virada social - análise textual e linguística, bem como a crítica ideológica - se mostram importantes, porém limitadas" (p. 488). Micciche continua, argumentando que essas ferramentas

\footnotetext{
restringem o escopo do que conta como social ao colocar em primeiro plano a natureza construída dos textos, objetos, atividades e corpos com pouca atenção para como essas construções interagem com sistemas naturais, biologia, animais e outras formas de matéria (MICCICHE, 2014, p. 488).
}

Para Micciche, e como eu tenho argumentado aqui, o que nós precisamos buscar são conceitos mais robustos de materialidade e de agência e envolvimento nãohumanos, algo que nos permitiria, por seu turno, redefinir colaborações translíngues e multimodais "como parcerias que incluem e excedem as intencionais estabelecidas entre pessoas" - parcerias que envolvem a mescla de "várias formas de matéria" (MICCICHE, 2014, p. 498), e que podem incluir, mas certamente não se limitam ao complexo processo de mistura e entrelace de palavras, sons, imagens, variedades de línguas, dialetos, convenções culturais, gêneros, páginas da internet, redes sociais, eletricidade, celulares, 
roupa, óculos, móveis, teclados, software, livros, papel, argila, memórias, rituais, corpos, nível de açúcar sanguíneo, comida, remédios, bactérias intestinais e animais de estimação.

\section{Sobre fluência composicional: trabalhando contra (e com) normas monolíngues/monomodais}

Em sua publicação de 2011, Horner et al. (2011) defendem uma abordagem para o ensino de escrita em que a proficiência do escritor é demonstrada através da variedade de práticas que o escritor mobiliza e usa criativamente, algo que requer que os alunos leiam "com paciência e respeito pela diferença percebida nos usos das línguas" ao mesmo tempo em que atentem, cuidadosa e criticamente, para "como escritores articulam dicção, sintaxe e estilo, bem como forma, registro e mídia” (HORNER et al., 2011, p. 304). A "fluência translíngue", os autores prosseguem de modo a sugerir, "seria definida como a habilidade de articular o uso de um repertório amplo e diversificado de recursos linguísticos e a capacidade de responder à diversidade de posições sociais e perspectivas ideológicas dos leitores" (p. 308). Em sua publicação de 2013, Lu e Horner recomendam que professores proponham questões que estimulem os alunos a pensarem "sobre o tipo de diferença pretendida através do trabalho com e sobre convenções em sua escrita, como e por que”, questões que, eles afirmam, "devem ecoar com a visão dos alunos sobre sua escrita e com as escolhas que todos os escritores têm que enfrentar" (LU; HORNER, 2013, p. 597).

Ao mesmo tempo em que concordo com o objetivo de preparar os alunos para a mobilização, a resposta e o uso criativo de um repertório muito mais amplo de convenções, variedades linguísticas e outros recursos para a construção de sentidos do que os tipicamente potencializados por cursos tradicionais de escrita universitária, eu sugiro aqui que o que a teoria e as práticas multimodais propiciam às práticas translíngues são potenciais para a ampliação de sua profundidade e de seu alcance, ao deslocar a atenção de "escritores" para "compositores" (ou de práticas de escrita para práticas de composição), permitindo, assim, a consideração de modos, materiais e 
práticas comunicativos/composicionais que podem incluir, mas certamente não se limitam à escrita ou à produção de textos escritos. Da mesma forma, a teoria e as práticas translíngues propiciam oportunidades para a ampliação da profundidade e alcance de estudos sobre multimodalidade ao nos impelir que consideremos textos, materiais, práticas comunicativas e convenções cross-culturais que podem incluir, mas não se limitam a falantes de Língua Inglesa e/ou outras variedades desta.

Um alargamento da consciência linguística, cross-cultural, material e modal propicia, então, um tipo de fluência comunicativa ou composicional, se me permite dizer. Essa consciência enriquecida pode ser facilitada ao solicitarmos aos alunos (ou a nós mesmos) que considerem a extensão da variedade de convenções, tecnologias, materiais e práticas que eles (e nós) tipicamente encontram em diferentes áreas ou domínios - na escola, no trabalho, em casa, em locais de adoração, compras, na comunicação online ou face a face, entre outros. Também é importante estimular a incorporação de textos, materiais e práticas do passado, de outras culturas e nações, bem como aquelas associadas a projeções pessoais futuras, uma vez que essa variedade de contextos históricos e cross-culturais provavelmente envolve a utilização de tecnologias, variedade linguísticas, gêneros, convenções e modos marcadamente diferentes do que os rotineiramente vivenciados no presente. Pedir que os alunos (e nós mesmos) considerem as diferenças entre textos, práticas e tecnologias comunicativas encontradas em um contexto sociocultural versus aqueles associados com outros ajuda a facilitar discussões sobre como e por que certas mudanças e transformações ocorrem e sobre como e por que certas formas linguísticas, convenções culturais, materiais e estratégias retóricas podem ser favorecidas e então buscadas e valorizadas (ou padronizadas) em detrimento de inúmeras outras que podem se imaginar capazes de fazer o mesmo ou um trabalho semelhante (ver também a discussão de Bawarshi (2016) sobre a utilização de perfis de gêneros nesse ponto).

Os defensores de uma abordagem translíngue para o ensino de escrita se preocupam com os limitados e limitantes potenciais das abordagens tradicionais aquelas que tratam, e também, perpetuam como "norma” uma situação linguisticamente homogênea e monolíngue, "em que se espera que escritores, falantes e leitores usem o inglês padrão ou um inglês americano editado...para exclusão de outras linguagens e 
variações linguísticas" (HORNER et al., 2011, p. 303). Estudiosos de multimodalidade e novas mídias têm expressado preocupações semelhantes sobre até que ponto as alternativas comunicativas têm sido (e frequentemente, apesar das demandas e potenciais propiciados pelas rápidas mudanças no cenário comunicativo, continuam a ser) limitadas por expectativas sobre como o discurso acadêmico e culto adequado deveria parecer ou soar, o que deveria ser e fazer. Consciente do risco que eu corro de ter meus argumentos compreendidos como a celebração de formas "alternativas" de representação, variedades linguísticas e modos comunicativos, e de tentar demonizar ou minimizar o valor e função dos tipos de texto (ou textos) que têm tradicionalmente sido considerados “monomodais/monolíngues", e então, adequadamente acadêmicos/cultos (por exemplo, impressos, alfabéticos, baseados em pesquisa, argumentativos, compostos em inglês padrão ou inglês americano editado), eu enfatizo aqui a importância de reconhecer os textos tradicionais/acadêmicos (como o que eu estou escrevendo agora) como apenas uma das opções comunicativas entre várias que podem ser buscadas. Temos pouco a ganhar ao inverter as hierarquias, substituindo um conjunto de sistemas de signos, estratégias de construção de sentido e de tecnologias comunicativas por outro, ao mesmo tempo que desvalorizamos o que veio antes. Do contrário, nós precisamos trabalhar para aumentar a conscientização quanto a/e facilidade com uma ampla variedade de opções comunicativas, com o objetivo de auxiliar os indivíduos a escolherem de forma sábia, crítica e objetiva os sistemas representacionais, os materiais e as variedades linguísticas que mais se adequam e são apropriados para os propósitos, potenciais e contextos do trabalho que eles pretendem desenvolver (SHIPKA, 2011).

Para tanto, o que os proponentes de uma abordagem translíngue e multimodal devem reconhecer é que nós compartilhamos uma compreensão de que as práticas comunicativas são sempre "multi" ou "trans" (multimodal/transmodal, multilingual/translíngue). E, tão importante quanto, que nós estamos comprometidos em reconhecer, honrar, aprender e trabalhar com (e não contra) a diferença e a diversidade comunicativa. Como eu defendi aqui, ambas as abordagens poderiam ser ainda mais ampliadas e enriquecidas se dessem mais atenção à materialidade e aos papéis que os humanos e não humanos desempenham no processo de construção de 
sentido. Ao fazer isso, nós podemos trabalhar para esclarecer os aspectos complexos e altamente distribuídos de toda prática comunicativa.

\section{Referências}

BAWARSHI, Anis. Beyond the Genre Fixation: A Translingual Perspective on Genre. College English, v.78, n.3, p.243-49, 2016.

BENNETT, Jane. Vibrant Matter: A Political Ecology of Things. Durham: Duke University Press, 2010.

CANAGARAJAH, A. Suresh. Toward a Writing Pedagogy of Shuttling between Multilingual Writers. College English, v.68, n.6, p. 589-6o4, 2006. - Translingual Writing and Teacher Development in Composition. College English, v. 78, n.3, p. 265-273, 2016.

CUSHMAN, Ellen. Translingual and Decolonial Approaches to Meaning Making. College English, v.78, n.3, p. 234-242, 2016.

FRAIBERG, Steven. Composition 2.o: Toward a Multilingual and Multimodal Framework. College Composition and Communication, v.62, n.1, p.10o-126, 2010.

GUERRA, Juan C. Cultivating a Rhetorical Sensibility in the Translingual Writing Classroom. College English, v. 78, n.3, p. 228-233, 2016.

HIGHMORE, Ben. Ordinary Lives: Studies in the Everyday. London: Routledge, 2010.

HORNER, Bruce; LOCKRIDGE, Tim; SELFE, Cynthia L. Translinguality, Transmodality, and Difference: Exploring Dispositions and Change in Language and Learning. [Digital monograph]. Intermezzo/Enculturation, 2015.

HORNER, Bruce; LU, Min-Zhan; ROYSTER, Jacqueline Jones; TRIMBUR, John. Language Difference in Writing: Toward a Translingual Approach. College English, v. 73, n.3, p. 303-313, 2011.

HORNER, Bruce; SELFE, Cynthia. Translinguality/Transmodality Relations: Snapshots from a Dialogue. Working paper series. University of Louisville, 2013.

JORDAN, Jay. Material Translingual Ecologies. College English, IIA, 2015, p.360-378. 
KRESS, Gunther. Before Writing: Rethinking the Paths to Literacy. New York: Routledge, 1997.

LATOUR, Bruno. Reassembling the Social: An Introduction to Actor-Network-Theory. Oxford: Oxford University Press, 2005.

LU, Min-Zhan; HORNER, Bruce. Translingual Literacy, Language Difference, and Matters of Agency. College English, v. 75, n.6, p. 582-607, 2013.

MICCICHE, Laura R. Writing Material. College English, v 76, n.6, p. 488-505, 2014.

PRIOR, Paul A.; HENGST, Julie A. (eds.). Exploring Semiotic Remediation as Discourse Practice. New York: Palgrave Macmillan, 2010.

PRIOR, Paul; SHIPKA, Jody. Chronotopic Lamination: Tracing the Contours of Literate Activity. In: BAZERMAN, Charles; RUSSELL, David (Eds.). Writing Selves, Writing Society: Research from Activity Perspectives. Fort Collins: WAC Clearinghouse, 2003. SHIPKA, Jody. Toward a Composition Made Whole. Pittsburgh: University of Pittsburgh, 2011.

SIRE, Geoffrey. English Composition as a Happening. Logan: Utah State University Press, 2002.

SOHAN, Vanessa Kraemer. 'But a quilt is more': Recontextualizing the Discourse(s) of the Gees Bend Quilts. College English, v. 77 A, p. 290-312, 2015. 